\title{
Changes in macrophage and inflammatory cytokine expressions during fracture healing in an ovariectomized mice model
}

Lin Chen ${ }^{1,2,3,4 \dagger}$, Shao Cheng ${ }^{1,2,3 \dagger}$, Kanghui Sun ${ }^{1,2,3 \dagger}$, Jing Wang ${ }^{1,2,3}$, Xinhua Liu ${ }^{5}$, Yongjian Zhao ${ }^{1,2,3}$, Junjie Yang ${ }^{1,2,3}$, Dongfeng Zhao ${ }^{1,2,3}$, Chunchun Xue $e^{1,2,3,4}$, Yuren Tao ${ }^{1,2,3}$, Shitian Zhao ${ }^{1,2,3}$, Hao Zhang ${ }^{1,2,3}$, Sheng Lu ${ }^{1,2,3}$, Qi Shi ${ }^{1,2,3}$, Yongjun Wang ${ }^{1,2,3}$ and Bing Shu $u^{1,2,3^{*}}$

\begin{abstract}
Background: Macrophages and inflammatory cytokines play important roles in bone fracture healing. However, the expression patterns of macrophages and inflammatory cytokines during fracture healing under the condition of postmenopausal osteoporosis have not been fully revealed.

Methods: Tibia transverse fracture was established 12 weeks after ovariectomy or sham operation in 16-week old female mice. Tibias were harvested before fracture or 1, 3, 5, 7, 14, 21, 28 days after fracture for radiological and histological examinations. M1/M2 inflammatory macrophages, osteal macrophages and gene expressions of tumor necrosis factor- $a$, interleukin- 6 , interleukin-1 $\beta$ and macrophage conversion related molecules in the fracture haematoma or callus were also detected.

Results: The processes of fracture healing, especially the phases of endochondral ossification and callus remodeling, were delayed in ovariectomized mice. The expressions of tumor necrosis factor-a and interleukin-6, but not interleukin-1 $\beta$, in the fracture haematoma or callus were disturbed. Expressions of tumor necrosis factor-a were decreased at 1, 14 and 21 days post-fracture (DPF), and were increased at 3, 5 and 7 DPF. Interleukin- 6 expressions at 1, 3 and 21 DPF were significantly increased. We found the decreases in M1 and M2 macrophages at 1 DPF of the initial inflammatory stage. M2 macrophages at 14 DPF of the middle stage and osteal macrophages at 14, 21 and 28 DPF of the middle and late stages of fracture healing were also reduced in ovariectomized mice.
\end{abstract}

Conclusions: The expressions of macrophages and inflammatory cytokines were impaired in ovariectomized mice, which might contribute partially to poor fracture healing.

Keywords: Ovariectomy, Fracture healing, Macrophage, Tumor necrosis factor-a, Interleukin-6

\footnotetext{
*Correspondence: siren17721101@163.com

${ }^{+}$Lin Chen, Shao Cheng and Kanghui Sun contributed equally to this work.

'Longhua Hospital, Shanghai University of Traditional Chinese Medicine,

Shanghai 200032, China

${ }^{2}$ Spine Institute, Shanghai Academy of Traditional Chinese Medicine,

Shanghai 200032, China

Full list of author information is available at the end of the article
}

C C The Author(s). 2021 Open Access This article is licensed under a Creative Commons Attribution 4.0 International License, which permits use, sharing, adaptation, distribution and reproduction in any medium or format, as long as you give appropriate credit to the original author(s) and the source, provide a link to the Creative Commons licence, and indicate if changes were made. The images or other third party material in this article are included in the article's Creative Commons licence, unless indicated otherwise in a credit line to the material. If material is not included in the article's Creative Commons licence and your intended use is not permitted by statutory regulation or exceeds the permitted use, you will need to obtain permission directly from the copyright holder. To view a copy of this licence, visit http://creativecommons.org/licenses/by/4.0/. The Creative Commons Public Domain Dedication waiver (http://creativecommons.org/publicdomain/zero/1.0/) applies to the data made available in this article, unless otherwise stated in a credit line to the data. 


\section{Background}

The process of fracture healing consists of inflammation stage, soft callus stage, hard callus stage and remodeling stage. Inflammation reaction in the initial phase of fracture which contains macrophages and inflammatory cytokines has been recognized critical for fracture healing. These inflammatory cells secrete a large number of cytokines which has been proved to play an important role in cell recruitment and angiogenesis as well as bone repair [1].

Macrophages can be categorized into inflammatory macrophage and resident macrophage. Inflammatory macrophages can be further classified into classically activated M1 phenotype and alternatively activated M2 phenotype, which can be shifted into each other under certain conditions [2]. In general, M1 macrophages produce inflammatory cytokines such as tumor necrosis factor- $\alpha$ (TNF- $\alpha$ ), interleukin- $1 \beta$ (IL-1 $\beta$ ) and interleukin6 (IL-6), and mediate inflammatory response, while M2 macrophages secret interleukin-10 and interleukin-1 receptor antagonist, and mediate tissue repair and resolution of inflammation [3]. Inflammatory macrophages are central mediators of the inflammatory response, the dynamic changes and balance between macrophage M1/ M2 play important roles in inflammatory regulation and tissue repair. Different from inflammatory macrophages, resident macrophages are present in all tissue with tissue-specific phenotypes and functional abilities [4, 5]. Resident macrophages in bone tissue located on periosteal and endosteal surface are termed osteal macrophages [6]. Studies have demonstrated that inflammatory macrophages were highly presented in the early anabolic phase; while osteal macrophages mature the bone callus, predominating in the late anabolic and remodeling phases during fracture healing $[7,8]$.

Macrophages and inflammation cytokines are proved to play important roles in callus formation, cartilage deposition and callus remodeling during bone fracture healing [7, 9-12]. Several studies have proved that the dysregulation of inflammatory environment during bone fracture could impair fracture healing, which was seen in diabetics, obesities and smokers [13-15]. Menopause, one of the most important factors in the pathogenesis of postmenopausal osteoporosis, was considered to induce a systemic chronic inflammatory reaction with the increase of TNF$\alpha$, IL-1 $\beta$, IL- 6 which were the major inflammatory factors during fracture healing [16]. Fracture healing in animal models of postmenopausal osteoporosis revealed a decrease in bone callus formation in the early stage, delay of endochondral bone formation and hard callus remodeling in the middle and late stages $[17,18]$. In addition, the pathological histology of postmenopausal osteoporotic fracture was similar to fracture with abnormal expression of macrophages or inflammatory cytokines $[17,18]$.
A systematic review analyzed the differences in inflammatory responses in normal and osteoporotic fractures, and found that it was inconclusive whether OVX animals have higher or lower local inflammatory response, and declared that there was a need for further studies to better understand the role of the inflammatory response in the healing cascade for potential immunomodulation to enhance osteoporotic fracture healing [19]. A recent study found that OVX impaired the innate immune response locally at the fracture site in rats. However, there was no study observing the dynamic changes in inflammatory response during osteoporotic fracture healing systematically, especially in the inflammation stage [20]. To address this issue, in this study, we established tibia fracture model in ovariectomized (OVX) mice, and observed the changes in macrophages and inflammatory cytokine expressions during different stages of fracture healing.

\section{Methods \\ Animal experimentation}

All applicable institutional and national guidelines for the care and use of animals were followed. The experimental protocols were performed with the approval of Institutional Animal Care and Use Committee of Shanghai University of Traditional Chinese Medicine (PZSHUTCM18121414). Female C57BL/6 mice were purchased from Charles River Company (Beijing, China). The mice were housed in environmentally controlled animal facilities at $22^{\circ} \mathrm{C}$ and humidity of 50 to $60 \%$, with a $12 \mathrm{~h}$ light/dark cycle, and were fed a commercial diet and distilled water ad libitum. The maximum caging density was five mice.

Following a 1-week acclimatization phase, 210 16week-old mice were randomly assigned to be bilaterally ovariectomized or to undergo sham surgery. Random numbers were generated using the standard $=$ RAND () function in Microsoft Excel. Four mice in the OVX group and 3 in the sham group died after ovariectomy or sham surgery. Twelve weeks after the surgery, mice were performed a mid-shaft transverse osteotomy fracture or sham surgery on the left tibias, and the tibias were fixed with 0.5 -mm-diameter intramedullary metallic pins. Another 14 mice, including 6 mice in the sham group and 8 in the OVX group, were excluded from following observations because comminuted fractures were made. Another 3 mice were used to supplement the sample size of the OVX group. All the mice were anaesthetized by intraperitoneal injection of ketamine $(67 \mathrm{mg} / \mathrm{kg})$ and xylazine $(5 \mathrm{mg} / \mathrm{kg})$ before fracture. After fracture, mice were allowed spontaneous recovery in warmed cages and unrestricted weight bearing. Mice were given Buprenorphine $(0.1 \mathrm{mg} / \mathrm{kg})$ for 3 days to relief any pain. 
Mice in each group were sacrificed by exsanguination and confirmation of death by cervical dislocation before fracture or $1,3,5,7,14,21,28$ days post-fracture (DPF) ( $n=12$ at each time point). Serum was separated for estradiol (E2) detection. The left tibias (6 from each group per time point) were harvested and fixed in $10 \%$ buffered formalin for $24 \mathrm{~h}$. After fixation, the specimens were washed by phosphate buffered saline, and stored in $75 \%$ ethanol at $4{ }^{\circ} \mathrm{C}$ for X-ray and micro-CT scanning. Following that, specimens were decalcified with $14 \%$ ethylene diaminetetraacetic acid disodium salt solution for 14 days, dehydrated and embedded. Four- $\mu \mathrm{m}$ thick serial sections were cut for histomorphometric study. The rest 6 tibias of each group were harvested for realtime polymerase chain reaction analysis (PCR).

\section{Blinding}

For each mouse, different investigators were involved as follows: 2 investigators (JW and XL) administered the random allocation of the mice, and 5 investigators (DZ, CX, YT, SZ and $\mathrm{HZ}$ ) performed bilaterally ovariectomy. Another 5 investigators (LC, SC, KS, YZ and JY) performed fracture and sacrifice procedures. Each investigator was responsible for part of the surgeries, including anesthesia, skin preparation and disinfection, model establishment, suturing, and resuscitation of the mice. LC, SC and KS assessed the results of the experiment. Two investigators (JW and SL) were responsible for statistical analysis of the data.

\section{Serum E2 detection}

Blood of mice in 0 DPF group was collected, and serum was separated after centrifugation at $3000 \mathrm{rpm}$ for 15 min at room temperature. Serum concentrations of E2 were measured using a commercially available kit (ml058533, MLBIO, China) according to the manufacturer's instructions.

\section{Three-dimensional (3D) reconstruction analyses}

The fractured tibias underwent X-ray photography first. A five-point radiographic scoring system was used to quantify fracture healing status at each time point by two researchers separately, and the average scores were adopted. The intramedullary metallic pins in the fractured tibias were then removed, and underwent scanning using a micro-CT imaging system ( $\mu$ CT80, Bassersdorf, Switzerland) with $10 \mathrm{~mm}$ slice increment. The source voltage was $55 \mathrm{kV}$ and the source current was $72 \mu \mathrm{A}$. The integration time was $300 \mathrm{~ms}$. A reconstruction of the bitmap data set was used to construct the 3D images of the fracture site using the built-in software (Scanco Holding AG, Brüttisellen, Switzerland). Total volume $\left(\mathrm{TV}, \mathrm{mm}^{3}\right)$, bone volume $\left(\mathrm{BV}, \mathrm{mm}^{3}\right)$ and the ratio of bone volume to total volume (BV/TV, \%) of the callus were also analyzed.

\section{Histological examination}

Alcian blue hematoxylin/orange G (ABH/OG) staining was used to evaluate the histological changes of callus at different time points. Briefly, dewaxed sections of each group were stained with alcian blue/hematoxylin solution for 30 min followed by a 15-s wash in 1\% ammonia solution and another 1-min wash in 95\% ethanol solution. The sections were then incubated in orange G/ eosin solution with phloxine B for $1 \mathrm{~min}$. After dehydration in ascending series of ethanol solution, clearing in xylene and mounting, all sections were analyzed by an Olympus VS120-S6-W slide loader system (Olympus, Japan).

\section{Antibodies}

The antibodies used for immunohistochemistry staining and immunofluorescence staining were purchased from Abcam (Shanghai, China) including anti-TNF- $\alpha$ antibody (ab6671, 1:200), anti-IL-1 $\beta$ antibody (ab9722, 1: 400), anti-IL-6 antibody (ab83339, 1:2000), anti-F4/80 antibody (ab6640, for immunohistochemistry staining, 1: 200), anti-F4/80 antibody (Alexa Fluor 488, ab204266, for immunofluorescence staining, 1:400), anti-inducible nitric oxide synthase (iNOS) antibody (Alexa Fluor 647, ab209027, 1:200), anti-Mannose receptor antibody (antiCD206, Alexa Fluor 647, ab195192, 1:200), anti-Galectin 3 (Mac-2) antibody (ab53082, 1:200).

\section{Immunohistochemistry staining}

Immunohistochemistry staining was used to evaluate the expressions of TNF- $\alpha$, IL-1 $\beta$, IL- 6, F4/80 and Mac2 in the fracture haematoma or callus. Deparaffinized and rehydrated serial sections were successively treated with $0.1 \%$ trypsin solution and $3 \% \mathrm{H}_{2} \mathrm{O}_{2}$ solution for $15 \mathrm{~min}$ at $37^{\circ} \mathrm{C}$. Sequentially the sections were incubated in diluted primary antibodies overnight at $4{ }^{\circ} \mathrm{C}$. Negative control sections were incubated in corresponding IgG solution instead. Then sections were incubated with secondary antibody and horseradish peroxidase (HRP)-streptavidin as instructed by the manufacturer (Polink-2 plus polymer HRP detection system kit, PV-9001/ PV-9004, ZSGB-BIO, Beijing, China). After staining with diaminobenzidine and counterstaining with hematoxylin, the images of the sections were obtained by an Olympus VS120-S6-W slide loader system, and were analyzed with an image Pro Plus 6.0 software (Media Cybernetics, PA, USA). Quantification of osteal macrophages $\left(\mathrm{F} 4 / 80^{+} \mathrm{Mac}-2^{-}\right)$was performed referring to the previous study [7]. For each section of the haematoma or callus, 6 regions were randomly selected for quantitative analysis, and the average value was calculated. For each group, 6 samples were included for statistical analyses. 


\section{Immunofluorescence staining}

To identify different types of macrophages in the fracture haematoma or callus tissue, dual immunofluorescence staining was performed with deparaffinized and rehydrated sections. Immunofluorescence staining was performed as described previously [21]. Briefly, sections were incubated with anti-F4/80 and anti-iNOS antibodies to identify M1 phenotypic macrophages; or incubated with anti-F4/80 and anti-CD206 antibodies to identify M2 phenotypic macrophages [22]. Finally, the sections were mounted in mounting medium with 4 ',6diamidino-2-phenylindole (DAPI, Ca H-1200, Vector, USA) and the images were obtained and analyzed by an Olympus VS120-S6-W slide loader system. For quantitative analysis of each section, positive stained cells of six random fields were counted and the average number of positive stained cells was calculated.

\section{Real-time PCR analysis}

Total RNA was isolated from the tissue located $2 \mathrm{~mm}$ distal and proximal to the fracture site. Reverse transcription was performed using a Primescript ${ }^{\text {tw }}$ RT reagent Kit (Takara Bio, Shanghai, China) and real-time PCR was performed in a total volume of $20 \mu \mathrm{l}$ solution containing $10 \mu \mathrm{l}$ SYBR Premix EX Taq (Takara Bio, Shanghai, China), $1 \mu$ diluted cDNA, 10pM forward and reverse primers. Primers specific for the genes were listed in Table 1. The mRNA expression of each gene was normalized to $\beta$-actin. The experiments were repeated at least three times.

Table 1 Sequences of PCR primers for specific genes

\begin{tabular}{|c|c|c|}
\hline Gene & & Sequences \\
\hline \multirow[t]{2}{*}{$\beta$-actin } & Forward & 5'-GGAGATTACTGCCCTGGCTCCTA-3' \\
\hline & Reverse & 5'-GACTCATCGTACTC CTGCTTGCTG-3' \\
\hline \multirow[t]{2}{*}{ Tnf-a } & Forward & 5'-CCTGTAGCCCACGTCGTAG-3' \\
\hline & Reverse & 5'-GGGAGTAGACAAGGTACAACCC-3' \\
\hline \multirow[t]{2}{*}{$\|-1 \beta$} & Forward & 5'-GGAGATTACTGCCCTGGCTCCTA-3' \\
\hline & Reverse & 5'-GACTCATCGTACTCCTGCTTGCTG-3' \\
\hline \multirow[t]{2}{*}{$\|-6$} & Forward & 5'-GACAAAGCCAGAGTCCTTCAGA-3' \\
\hline & Reverse & 5'-GTCTTGGTCCTTAGCCACTCC-3' \\
\hline \multirow[t]{2}{*}{ Cd16 } & Forward & 5'-CAGAATGCACACTCTGGAAGC-3' \\
\hline & Reverse & 5'-GGGTCCCTTCGCACATCAG-3' \\
\hline \multirow[t]{2}{*}{ Cd206 } & Forward & 5'-GGAAACGGGAGAACCATCAC-3' \\
\hline & Reverse & 5'-GGCGAGCATCAAGAGTAAAG-3' \\
\hline \multirow[t]{2}{*}{ Mcsf } & Forward & 5'-AACAGCTTTGCTAAGTGCTCTA-3' \\
\hline & Reverse & 5'-ACTTCCACTTGTAGAACAGGAG-3' \\
\hline \multirow[t]{2}{*}{ Mcp-1 } & Forward & 5'-TTाTTGTCACCAAGCTCAAGAG-3' \\
\hline & Reverse & 5'-TTCTGATCTCATTTGGTTCCGA-3' \\
\hline \multirow[t]{2}{*}{$\|-4$} & Forward & 5'-AGT GAG CTC GTC TGT AGGGC-3' \\
\hline & Reverse & 5'-CAGGCA TCG AAA AGC CCG AA-3' \\
\hline
\end{tabular}

\section{Statistical evaluation}

All data were presented as mean \pm standard deviation and were analyzed by GraphPad Prism statistical software (version 6.01, California Corporation, America) as appropriate. Data sets was performed a Shapiro-Wilk test for normality and confirmed a comparison of variances test for Homogeneity. ANOVA with Turkey's post hoc test or unpaired Student's t tests was performed for comparison between two groups. $P$ value $<0.05$ was considered statistically significant.

\section{Results}

\section{Fracture healing was delayed in OVX mice}

To confirm the establishment of OVX model, serum concentrations of E2 of OVX mice and sham mice were detected at 0 DPF, which was 12 weeks after ovariectomy. E2 concentration of OVX mice was obviously decreased compared with that of sham mice (Fig. 1a).

To reveal the morphological differences in callus between OVX mice and sham mice, 3D reconstructions (Fig. 1b) were performed. There was no obvious difference between the two groups until 14 DPF. At this time point, callus formation of the sham mice was evident with bridge connecting the fracture gap and the fracture line was almost invisible. However, the fracture gap was still obvious in OVX mice. In addition, the callus of sham mice became small at 21 and $28 \mathrm{DPF}$, while it was still obvious in OVX mice. These results were consistent with the X-ray findings (Additional Figure 1) and suggested a delayed fracture healing process in OVX mice. Quantitative analyses showed that both callus TV and BV of OVX group were increased in the tendency compared with that of sham group, though no significance was shown (Fig. 1c and d). BV/TV values (21 and 28 DPF) of OVX group were significantly decreased (Fig. 1e, $p<0.05)$, indicating the bone mass of healed tibias in OVX mice was decreased.

\section{Endochondral ossification and callus remodeling were impaired in OVX mice}

$\mathrm{ABH} / \mathrm{OG}$ staining revealed that proteoglycan-rich cartilage tissue emerged in both callus of sham mice and OVX mice from 5 DPF. At 14 DPF, cartilage tissue fully bridged the fracture gap, indicating the formation of cartilaginous callus. Then cartilaginous callus were gradually moved away and woven bone-like matrix formed at the edge of the callus. At $21 \mathrm{DPF}$, cartilage tissue of callus was almost completely resorbed in sham mice. However, cartilage tissue of callus in OVX mice was less at $14 \mathrm{DPF}$ and was still obvious at $21 \mathrm{DPF}$. At $28 \mathrm{DPF}$, callus had remodeling of the callus was almost completed in sham mice while there was still plenty of spongy bone tissue in the callus of OVX mice (Fig. 2a). Histological quantification also confirmed increased 


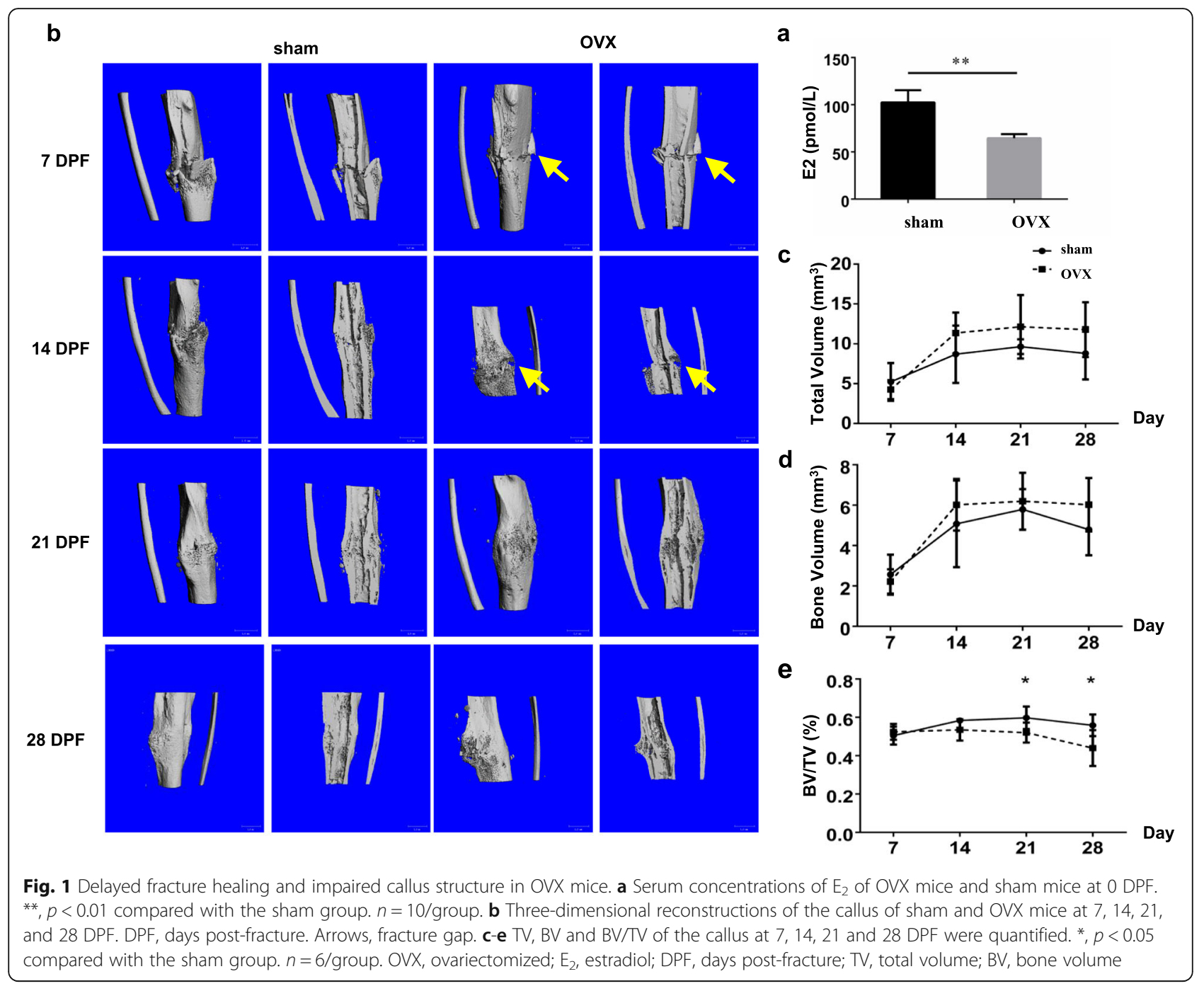

cartilage tissue in the callus of OVX mice at $21 \mathrm{DPF}$ (Fig. $2 \mathrm{~b}, p<0.05$ ), which suggested a delay in endochondral ossification process during fracture healing in OVX mice.

TNF- $\alpha$ and IL- 6 but not IL-1 $\beta$ expression were impaired in OVX mice during fracture healing

The protein and gene expressions of inflammatory cytokines, including TNF- $\alpha$, IL- $1 \beta$ and IL- 6 , in the fracture haematoma or callus of both sham and OVX mice were detected by immunohistochemical analysis and real-time PCR respectively.

Before fracture, TNF- $\alpha$ protein was rarely found in the tibias of sham and OVX mice. In sham mice, expression of TNF- $\alpha$ was increased in the periosteum and bone marrow surrounding the fracture site at $1 \mathrm{DPF}$, and then was decreased at $3 \mathrm{DPF}$ and 5 DPF. From $7 \mathrm{DPF}$, dramatic TNF- $\alpha$ expression was found in the callus and became even intensive and concentrated at 14 DPF, especially in the bridged gap. TNF- $\alpha$ expression was then gradually decreased from 21 DPF. In OVX mice, small amount of positive staining was found in the periosteum at $1 \mathrm{DPF}$. After a temporary reduction at $3 \mathrm{DPF}, \mathrm{TNF}-\alpha$ expression was gradually increased again until 7 DPF. At 14 DPF when TNF- $\alpha$ expression in sham mice reached the peak, TNF- $\alpha$ expression in OVX mice began to decrease (Fig. 3a). The quantification result showed that, compared with that of sham mice, TNF- $\alpha$ expression in the callus of OVX mice were significantly lower at 1, 14, $21 \mathrm{DPF}$, and were higher at 3, 5, 7 DPF (Fig. 3b; 1, 3, 5 and 14 DPF, $p<0.05 ; 7$ and $21 \mathrm{DPF}, p<0.01$ ).

IL- 6 protein was also rarely found in the tibias of sham mice before fracture. After fracture, plenty of IL- 6 positive staining emerged in the surrounding tissue of fracture site, and became less gradually as the following fracture healing process went on. In OVX mice, IL-6 expression was always highly expressed, especially at the early stage of fracture healing (Fig. 4a). Quantification data also showed that the IL-6 expression level reached the peak as early as $1 \mathrm{DPF}$, and was gradually decreased 


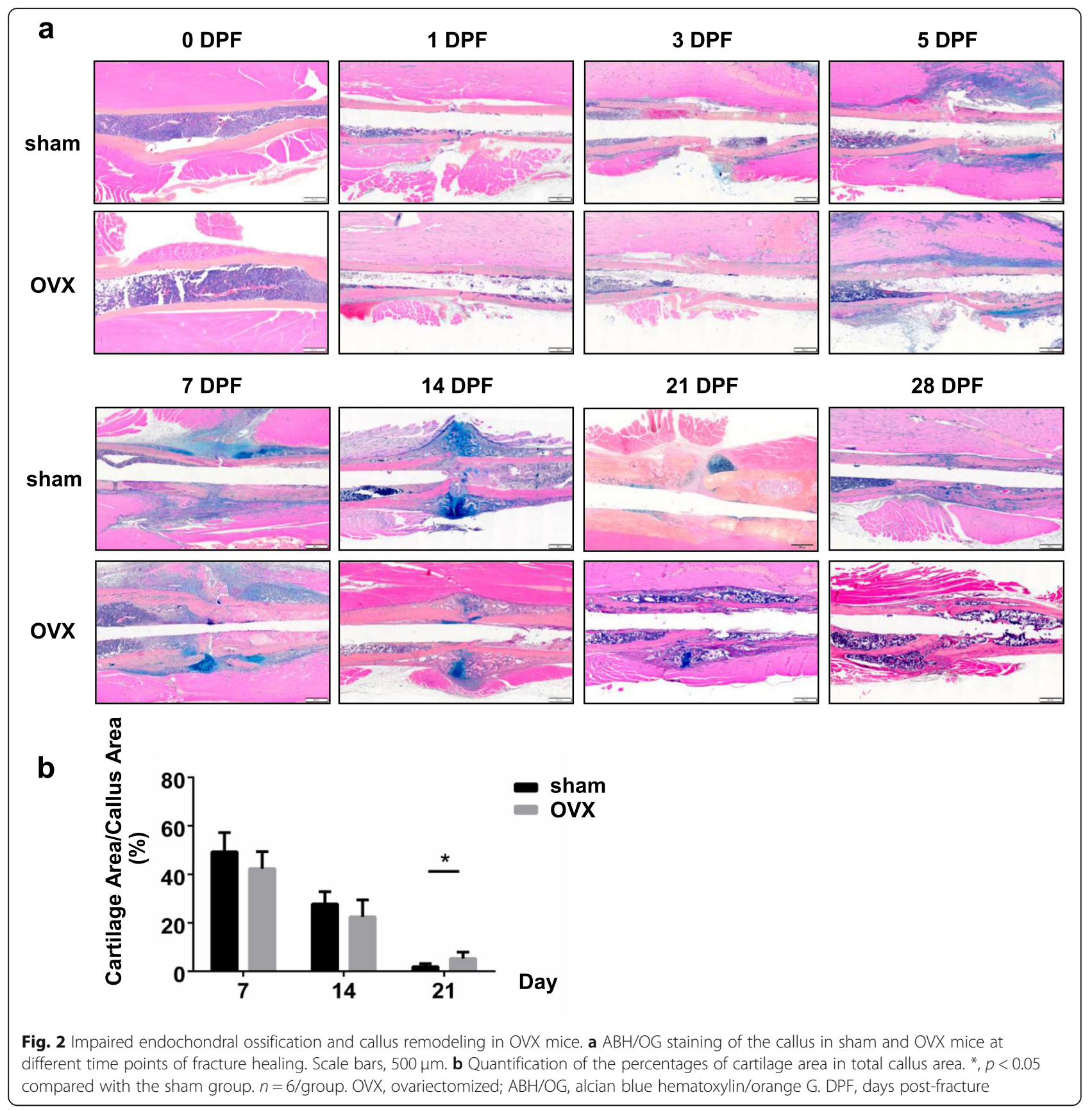

to in a very slow rate. IL- 6 expression in callus of OVX mice was significantly higher at $0,1,3$ and $21 \mathrm{DPF}$ (Fig. 4b; 0,1 and $3 \mathrm{DPF}, p<0.01 ; 21 \mathrm{DPF}, p<0.05$ ).

We also examined the mRNA levels of these inflammatory genes in callus of sham and OVX mice. It was showed that there were two peaks (1 DPF and 14 DPF) in Tnf- $\alpha$ expression and one peak (1 DPF) in Il-6 expression (Figs. $3 \mathrm{c}$ and $4 \mathrm{c}$ ). Tnf- $\alpha$ expression was significantly decreased at 1, 14, $21 \mathrm{DPF}$, and increased at 3, 5 and 7 DPF (Fig. 3c; 1, 3, 5, 7 and 21 DPF, $p<0.01 ; 14$ DPF, $p<$ $0.05)$ in OVX mice. In addition, Il-6 expression was increased significantly at $0,1,3$ and 21 DPF (Fig. 4c;0 and $3 \mathrm{DPF}, p<0.01 ; 1$ and $21 \mathrm{DPF}, p<0.05)$ in OVX mice.

However, no significant differences in both gene and protein expressions of IL- $1 \beta$ in callus was shown between sham and OVX mice, though IL-1 $\beta$ was highly expressed in callus after fracture (Additional Figure 2).

Both inflammatory macrophages and osteal macrophages were impaired in OVX mice during fracture healing Since the expressions of inflammatory cytokines during fracture healing were impaired in OVX mice, we assessed 


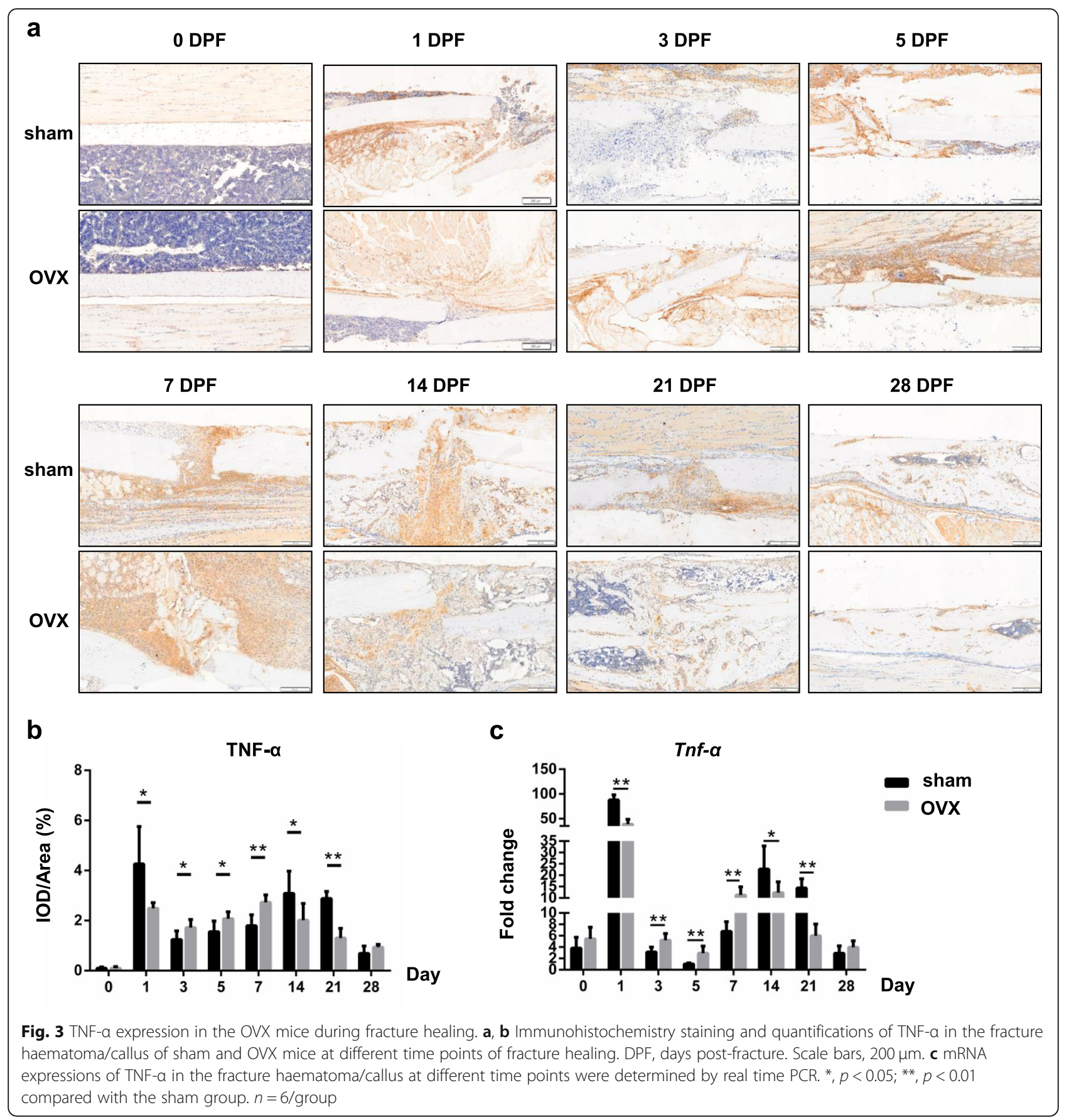

the changes in inflammatory macrophage status during fracture healing, referring to M1 macrophage and M2 macrophage which were the main sources of inflammatory cytokines. The expression levels of $C d 16$ and $C d 206$, markers of M1 and M2 macrophage respectively, in the fracture haematoma or callus were also detected. Cd16 expression was significantly decreased at $1 \mathrm{DPF}$ only (Fig. 5a; 1 DPF, $p<0.01$ ), and $C d 206$ expression was decreased at 1 and 14 DPF in OVX mice (Fig. 5b; 1 DPF, $p<0.05$; 14DPF. $p<0.01)$.
Dual immunofluorescence staining for F4/80 and iNOS was performed to detect M1 macrophages at fracture site as well as F4/80 and CD206 for M2 macrophages, and the results were consistent with the results of the expression levels of Cd16 and Cd206 (Fig. 5c and d). Compared with the sham mice, OVX mice showed less M1 and M2 macrophages in the fracture haematoma at $1 \mathrm{DPF}$, and also less M2 macrophages in the callus at 14 DPF (Fig. 5a), which was further confirmed by quantification results (Fig. $5 \mathrm{~d}, p<0.05$ ). Gene expressions of some molecules 


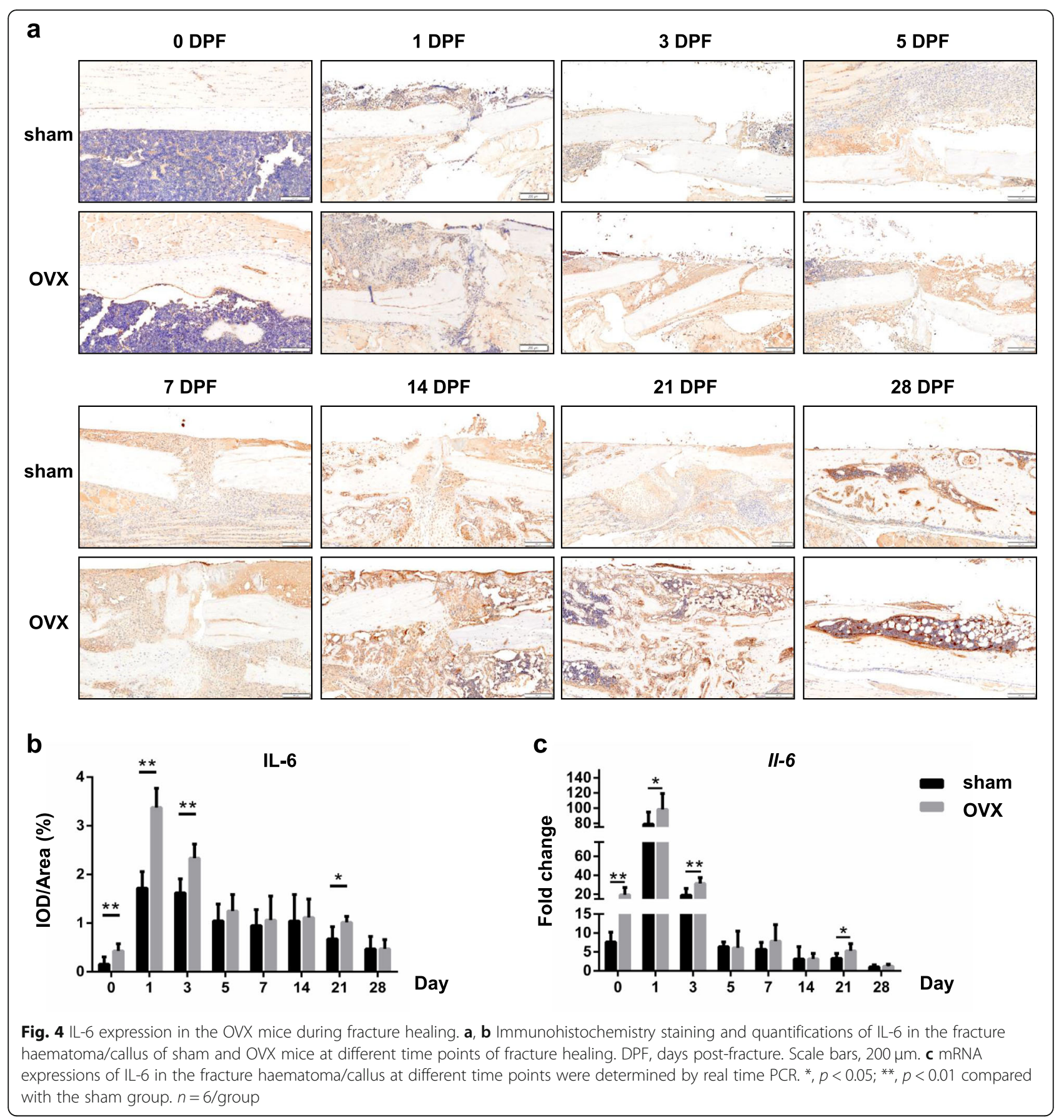

involved in macrophage differentiation were also observed. The gene expression level of macrophage-colony stimulating factor (M-CSF) in the fracture haematoma of OVX mice was dramatically decreased compared with sham group at 1 DPF (Fig. 5e, $p<0.01$ ), but no significant difference between these two groups at 14 DPF was revealed. Expression level of monocyte chemoattractant protein-1 (MCP-1) mRNA in the fracture haematoma or callus of OVX mice was significantly increased compared with sham group at both 1 DPF and 14 DPF (Fig. 5f, $p<0.01$ ), while $\mathrm{Il}-4$ expression at $14 \mathrm{DPF}$ was decreased (Fig. 5g, $p<0.01$ ).

Osteal macrophages have been detected in multiple stages of fracture healing and been proved to contribute to fracture healing though regulating osteoblast functions [6]. Here we identified osteal macrophages from inflammatory macrophages through immunohistochemical staining for F4/80 and Mac-2 with series sections. Cells with positive F4/80 staining and negative Mac-2 staining were considered osteal macrophages $\left(\mathrm{F} 4 / 80^{+}\right.$ 

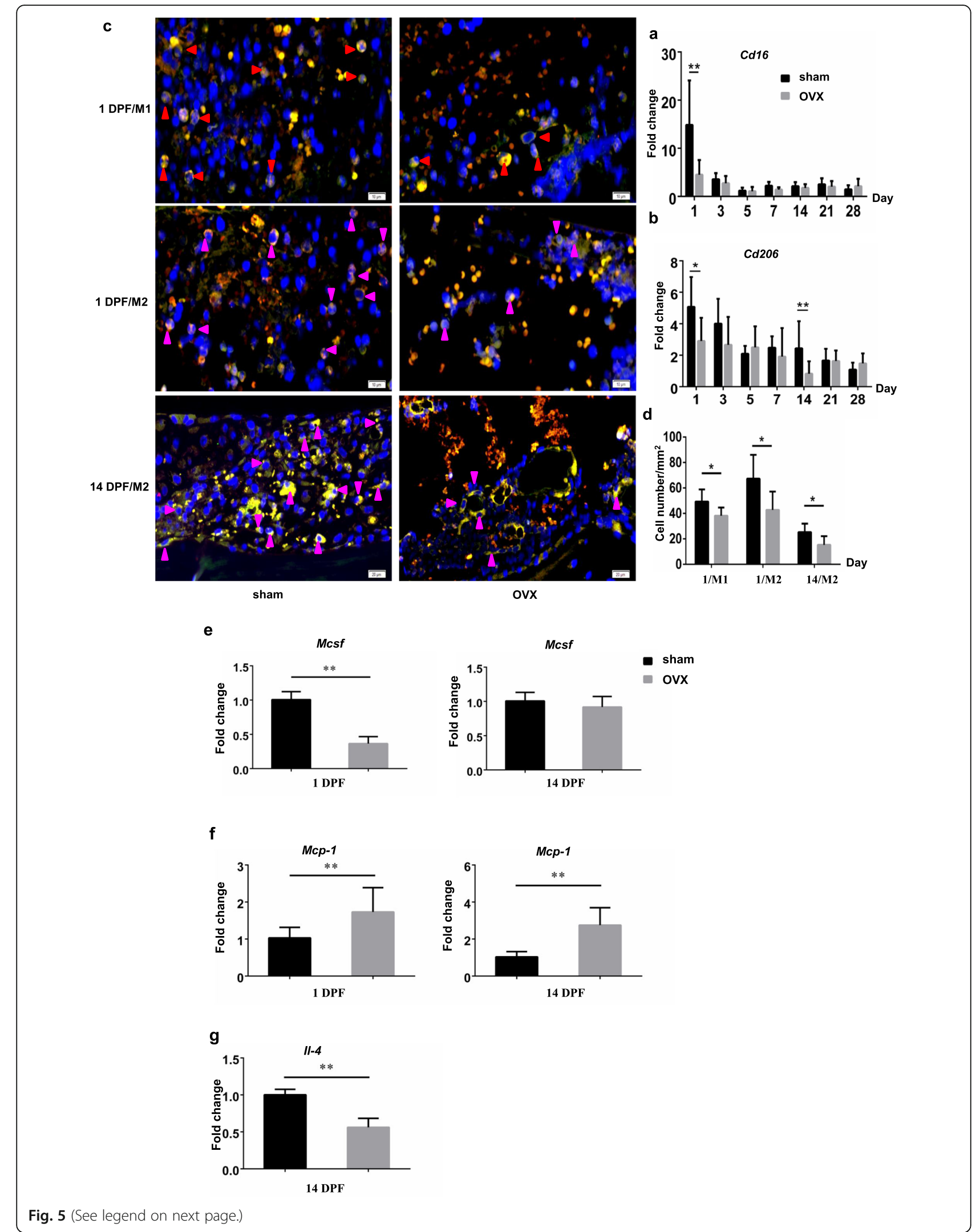
(See figure on previous page.)

Fig. 5 Impaired inflammatory macrophage formation in the OVX mice during fracture healing. a, b mRNA expressions of M1 (Cd16) and M2 (Cd206) macrophage specific markers in the fracture haematoma/callus of sham and OVX groups. *, $p<0.05 ;{ }^{*}, p<0.01$ compared with the sham group. $n=6 /$ group. c Dual immunofluorescence staining for M1/M2 macrophages in the fracture haematoma/callus of sham and OVX mice. Blue, DAPI positive nucleus. Red arrow heads, M1 macrophages. Pink arrow heads, M2 macrophages. $\mathbf{d}$ Numbers of M1 and M2 macrophages in the fracture haematoma/callus of were quantified. ${ }^{*}, p<0.05$ compared with the sham group. $n=6 /$ group. e-g mRNA expressions of MCSF, MCP- 1 and IL-4 in the fracture haematoma/callus of sham and OVX groups. ${ }^{*}, p<0.01$ compared with the sham group. $n=3 /$ group

Mac-2 $2^{-}$) [23]. In both sham and OVX mice, there were very few $\mathrm{F} 4 / 80^{+} \mathrm{Mac}-2^{-}$macrophages in the early stage of fracture healing (data not shown). More $\mathrm{F} 4 / 80^{+} \mathrm{Mac}-$ $2^{-}$macrophages emerged on the surface of newly formed bone marrow cavities until 14 and 21 DPF when endochondral ossification occurred within the callus. As callus remodeling went on, $\mathrm{F} 4 / 80^{+} \mathrm{Mac}-2^{-}$macrophages became to decrease again (Fig. 6a). These findings were consistent with the results of previous study [7]. Being different from that of sham mice, $\mathrm{F} 4 / 80^{+} \mathrm{Mac}-2^{-}$macrophages could rarely be detected in the middle and late stage of fracture healing in OVX mice (Fig. 6a). The differences in $\mathrm{F} 4 / 80^{+} \mathrm{Mac}-2^{-}$macrophage numbers between sham mice and OVX mice were confirmed by quantification (Fig. 6b, $p<0.01$ ).

\section{Discussion}

The expressions of inflammatory cytokines during fracture healing follow a biphasic pattern, with a transient peak in the initial inflammatory phase, and a second peak during chondrocyte maturation and endochondral ossification [1, 24]. Being different from those secreted by inflammatory cells in the initial phase, the inflammatory cytokines expressed during chondrocyte maturation and endochondral ossification are mainly synthesized by osteoblasts, chondrocytes and other cells, which can

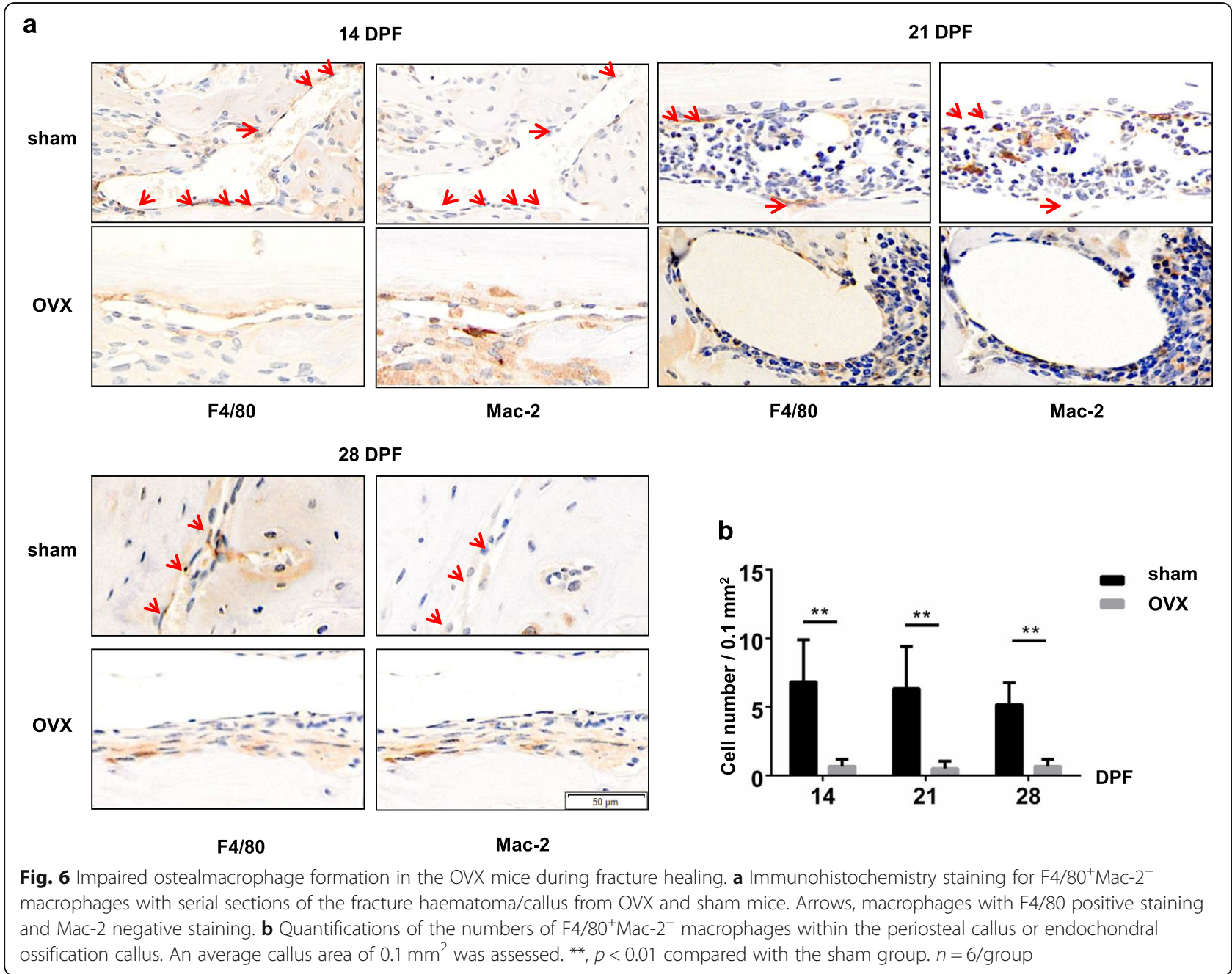


result the second peak in the middle and later stage of fracture $[25,26]$. In murine fracture models, inflammatory response of TNF- $\alpha$, IL- $1 \beta$ and IL- 6 peak $24 \mathrm{~h}$ following the fracture injury and decline to baseline levels rapidly by $72 \mathrm{~h}$. Thereafter, a second peak in TNF$\alpha$, IL-1 $\beta$ expression occur approximately 14 days following the fracture injury $[24,27]$.

Fracture healing comprises two bone repair processes: intramembranous and endochondral bone formation. The roles of inflammatory cytokines in intramembranous bone formation can be summarized into two aspects. On one hand, inflammatory cytokines acted as chemokines which were responsible for bone marrow stromal cell (bMSC) recruitment [28]. On the other hand, inflammatory cytokines could promote intramembranous bone formation directly by inducing bMSCs osteogenic differentiation [29]. Endochondral bone formation includes a series of processes such as cartilage proliferation, maturation, hypertrophy and apoptosis, and inflammatory cytokines also play an important role [30]. Clinical studies confirmed that inflammatory cytokines such as TNF- $\alpha$, IL-1 $\beta$ and IL-6 were highly expressed in osteoarthritis, which induced chondrocyte apoptosis and destroy articular cartilage [31, 32]. TNF- $\alpha$ could promote apoptosis of chondrocytes by upregulating the apoptotic genes in chondrocytes [33], and chondrocyte apoptosis and resorption of the mineralized cartilage during the endonchondral period were delayed in TNF- $\alpha$ receptor deficient mice [34].

In our study, TNF- $\alpha$ expression was dysregulated during fracture healing in OVX mice. Reduced transient expression in the initial inflammation phase and endochondral ossification phase might lead to decreased abilities in bMSC recruitment and osteogenic differentiation as well as chondrocyte maturation and endochondral ossification. Furthermore, TNF- $\alpha$ expression in OVX mice was consistently up-regulated at other time points except for the initial inflammation phase and endochondral ossification phase of fracture healing. TNF- $\alpha$ has dual roles on osteogenic differentiation depended on the exposure time. Huang et al. [29] reported that long-term treatment of TNF- $\alpha$ induced inhibitory effect on osteogenic differentiation in vitro while short-term promoted osteogenic differentiation. Also TNF- $\alpha$ was proved with strong ability to induce osteoclast formation [35]. Therefore, consistent up-regulated TNF- $\alpha$ expression in OVX mice could contribute partially to decreased trabecular bone number and sparser structure of callus, which was consistent with previous studies $[17,36]$.

IL-6 levels in the plasma and fracture callus peaked as early as $6 \mathrm{~h}$ after fracture, and progressively declined to a low level in $72 \mathrm{~h}$. Compared with sham mice, plasma IL6 expression in OVX mice was even higher at $6 \mathrm{~h}$ after fracture [37], which might due to the increase of neutrophils
[38]. In this study, IL-6 expression in OVX mice was increased before fracture, and the increase was even obvious during the early stage of fracture which was consistent with the previous finding. Furthermore, there was almost no significant difference in IL-6 expression between OVX and sham mice during the middle and late stages of fracture healing. IL-6 is a potential inducer of osteoclast differentiation independent of receptor activator of nuclear factor kappa-B ligand (RANKL) [39], and can be produced by plenty of cells under physiological and pathological conditions including immune-mediated cells, mesenchymal cells, vascular endothelial cells, fibroblasts, and so on. Unlike TNF- $\alpha$, the action of IL- 6 signaling is dependent on the availability of RANKL in the microenvironment [40].

However, no change in IL-1 $\beta$ expression between sham mice and OVX mice was found. This was also consistent with previous animal study that during the fracture healing of IL- $1 \beta$ receptor $\left(\mathrm{I} l r 1^{-/-}\right)$mice, no differences in callus, cartilage or bone matrix production could be found [41].

Previous studies have demonstrated macrophages presented in multiple stages of fracture healing [7, 8]. Inflammatory macrophages were observed in the early anabolic events of femoral fracture healing; the phenotype changed during the first 3 days from predominantly M1 to M2, and M2 macrophages dominated the gap area at 7 days. Osteal macrophages were predominantly activated at day 14 to 21 after fracture [7, 42]. In our study, both M1 and M2 macrophages were predominantly presented in the initial phase, and osteal macrophages presented in the middle and late stage during fracture healing in sham mice. OVX led to deceased M1 and M2 macrophages in the initial phase and rarely detected osteal macrophages in the middle and late stages of fracture healing. Moreover, OVX mice also showed fewer M2 macrophages in the endochondral ossification phase of fracture healing. M-SCF has been confirmed a significant contributor to differentiation and maintenance of macrophage multiple populations [43], and is typically used in vitro to differentiate human monocytes into macrophages [44]. Therefore, the dramatically decreased expression of M-SCF at 1 DPF in OVX mice may partially contributed to the loss of both M1 and M2 macrophages in the initial phase of bone fracture. IL- 4 is capable of stimulating M2 polarization, while MCP-1 is an inhibitory factor for M2 polarization from bone marrow-derived macrophages $[45,46]$. Increased expression of MCP-1 and decreased expression of IL-4 could also partially explain the phenotype of M2 macrophage reduction at the early and middle phases of fracture healing.

M1 macrophages can secrete pro-inflammatory cytokines such as TNF- $\alpha$, promoting angiogenesis and recruiting 
bMSCs. M2 macrophages participate in phagocytosing apoptotic cells, dissolving thrombus and promoting tissue repair [47]. In addition, M2 macrophages were reported a higher angiogenic potential compared to other macrophage subsets [48]. In vitro experiment also evidenced increased osteogenic markers expression and bone mineralization of M2 macrophage co-cultured bMSCs [49]. Therefore, decreased inflammatory macrophages as well as lower expressions of inflammatory cytokines, especially TNF- $\alpha$, disturbed the initiation inflammatory responses of fracture healing, and deceased M2 macrophages could also impaired angiogenesis, osteogenesis, and endochondral ossification in OVX mice. Osteal macrophages were predominantly presented within the maturing/remodeling hard callus during fracture; depletion of osteal macrophages during bone healing has been demonstrated impaired endochondral callus formation and osteoblast mineralization using the Mafia transgenic mouse model $[7,8,50]$. However, the exact molecular mechanisms by which osteal macrophages affect callus remodeling have not been fully addressed.

There were still some limitations of this study. Firstly, we only examined the expressions of several critical cytokines due to limited samples obtained from mice models, including TNF- $\alpha$, IL- $1 \beta$ and IL- 6 . There were plenty of inflammatory or pro-inflammatory cytokines presenting in the process of fracture healing, and more studies should be carried out to totally reveal the expression patterns of these cytokines. Secondly, activated resident macrophages including osteal macrophages, are able to shift into pro-inflammatory M1 macrophages or antiinflammatory M2 macrophages by different cytokines [51]. Therefore, the cell shift between inflammatory macrophages and osteal macrophages continuously occurred during the process fracture healing. Ovariectomy leads to a chronic increase in systemic inflammation, and it may probably result in dysregulation of the cell shift. However, this issue was not confirmed in the current study. Thirdly, due to the limited sample size, mechanical test which could contribute the evaluation of the quality of fracture healing was not included in this study. Lastly, we selected a small sample size at each time point since it was the first time to evaluate the changes in macrophages and inflammatory cytokine expressions during fracture healing between sham and OVX mice, which might limit greater extrapolation of our results.

\section{Conclusions}

Taken together, ovariectomy in mice led to irregular macrophages and inflammatory cytokine expressions during fracture healing, especially in the initial inflammatory phase and the endochondral ossification phase, which might impair fracture healing in OVX mice. It was suggested that irregular inflammatory responses might occur during fracture healing process of postmenopausal women.

\section{Abbreviations}

TNF-a: Tumor necrosis factor- $\alpha$; IL-1 $\beta$ : Interleukin-1 $\beta$; IL-6: Interleukin-6; OVX: Ovariectomized; DPF: Days post-fracture; E2: Estradiol; PCR: Polymerase chain reaction analysis; TV: Total volume; BV: Bone volume; ABH/OG: Alcian blue hematoxylin/orange G; iNOS: Inducible nitric oxide synthase; HRP: Horseradish peroxidase; DAPI: 4',6-diamidino-2-phenylindole; MCSF: Macrophage-colony stimulating factor; IL-4: Interleukin-4; MCP-

1: Monocyte chemoattractant protein-1; bMSC: Bone marrow stromal cell; RANKL: Receptor activator of nuclear factor kappa-B ligand

\section{Supplementary Information}

The online version contains supplementary material available at https://doi. org/10.1186/s12891-021-04360-z.

Additional file 1: Figure 1. Radiographic changes of the tibias in sham and OVX mice at different time points of fracture healing.

Additional file 2: Figure 2. Immunohistochemistry staining and realtime PCR for the protein and mRNA expressions of $\mathrm{IL}-1 \beta$ in the fracture haematoma/callus of sham and OVX mice.

\section{Acknowledgements}

Not applicable.

\section{Authors' contributions}

BS and YW designed the study. LC, SC, KS, XL, YZ, JY, DZ, CX, YT, SZ, HZ and $S L$ contributed to the experimental work. LC, SC, KS prepared the first draft of the paper. BS, YW and QS critically revised the manuscript. JW and SL were responsible for statistical analysis of the data. All authors revised the paper critically for intellectual content and approved the final version. All authors read and approved the final manuscript.

\section{Funding}

this work was partially supported by the National Key R\&D Program of China (2018YFC1704302), the National Natural Science Foundation of China (81973876, 81929004, 81804122, 81730107 and 82004183), the Program for Innovative Research Team, Ministry of Science and Technology of China (2015RA4002), the Program for Innovative Research Team, Ministry of Education of China (IRT1270), the Shanghai Sailing Program (19YF1445300), the Three Year Action Program, Shanghai Municipal Health Commission (ZY (2018-2020)-CCCX-3003), the research program of Shanghai Municipal Health Commission (20174Y0192) and the Postgraduates' Training Project of Shanghai University of Traditional Chinese Medicine (Y2019010). The funding bodies had no role in the design of the study, data collection, analyses, interpretation of data or writing the manuscript.

Availability of data and materials

the datasets used and/or analyzed during the current study are available from the corresponding author on reasonable request.

\section{Declarations}

Ethics approval and consent to participate

all applicable institutional and national guidelines for the care and use of animals were followed. The experimental protocols were performed with the approval of Institutional Animal Care and Use Committee of Shanghai University of Traditional Chinese Medicine (PZSHUTCM18121414).

Consent for publication

Not applicable.

Competing interests

the authors declare that they have no competing interests.

\section{Author details}

'Longhua Hospital, Shanghai University of Traditional Chinese Medicine, Shanghai 200032, China. ${ }^{2}$ Spine Institute, Shanghai Academy of Traditional Chinese Medicine, Shanghai 200032, China. ${ }^{3}$ Key Laboratory, Ministry of Education of China, Shanghai 200032, China. ${ }^{4}$ Shanghai Municipal Hospital of Traditional Chinese Medicine, Shanghai University of Traditional Chinese 
Medicine, Shanghai, China. ${ }^{5}$ Experiment Center for Science and Technology, Shanghai University of Traditional Chinese Medicine, Shanghai 201203, China.

\section{Received: 14 November 2020 Accepted: 12 May 2021 Published online: 28 May 2021}

\section{References}

1. Gerstenfeld LC, Cullinane DM, Barnes GL, Graves DT, Einhorn TA. Fracture healing as a post-natal developmental process: molecular, spatial, and temporal aspects of its regulation. J Cell Biochem. 2003;88(5):873-84. https://doi.org/10.1002/jcb.10435.

2. Martinez FO, Sica A, Mantovani A, Locati M. Macrophage activation and polarization. Front Biosci. 2008;13(13):453-61. https://doi.org/10.2741/2692.

3. Gordon S, Martinez FO. Alternative activation of macrophages: mechanism and functions. Immunity. 2010;32(5):593-604. https://doi.org/10.1016/j. immuni.2010.05.007.

4. Wynn TA, Chawla A, Pollard JW. Macrophage biology in development, homeostasis and disease. Nature. 2013;496(7446):445-55. https://doi.org/10.1 038/nature12034.

5. Hashimoto D, Chow A, Noizat C, Teo P, Beasley MB, Leboeuf M, et al. Tissueresident macrophages self-maintain locally throughout adult life with minimal contribution from circulating monocytes. Immunity. 2013;38(4): 792-804. https://doi.org/10.1016/j.immuni.2013.04.004.

6. Chang MK, Raggatt $L$, Alexander KA, Kuliwaba JS, Fazzalari NL, Schroder K, et al. Osteal tissue macrophages are intercalated throughout human and mouse bone lining tissues and regulate osteoblast function in vitro and in vivo. J Immunol. 2008;181(2):1232-44. https://doi.org/10.4049/jimmunol.1 81.2.1232.

7. Raggatt $L$, Wullschleger ME, Alexander KA, Wu ACK, Millard SM, Kaur S, et al. Fracture healing via periosteal callus formation requires macrophages for both initiation and progression of early Endochondral ossification. Am J Pathol. 2014;184(12):3192-204. https://doi.org/10.1016/j.ajpath.2014.08.017.

8. Alexander KA, Chang MK, Maylin ER, Kohler T, Muller R, Wu AC, et al. Osteal macrophages promote in vivo intramembranous bone healing in a mouse tibial injury model. J Bone Miner Res. 2011;26(7):1517-32. https://doi.org/1 $0.1002 / j b m r .354$.

9. Mountziaris PM, Mikos AG. Modulation of the inflammatory response for enhanced bone tissue regeneration. Tissue Eng B Rev. 2008;14(2):179-86. https://doi.org/10.1089/ten.teb.2008.0038.

10. Lehmann W, Edgar CM, Wang K, Cho TJ, Barnes GL, Kakar S, et al. Tumor necrosis factor alpha (TNF-alpha) coordinately regulates the expression of specific matrix metalloproteinases (MMPS) and angiogenic factors during fracture healing. Bone. 2005;36(2):300-10. https://doi.org/10.1016/j.bone.2 004.10.010.

11. Yang X, Ricciardi BF, Hernandez-Soria A, Shi Y, Pleshko Camacho N, Bostrom MP. Callus mineralization and maturation are delayed during fracture healing in interleukin-6 knockout mice. Bone. 2007;41 (6):928-36. https://doi. org/10.1016/j.bone.2007.07.022

12. Abou-Khalil R, Yang F, Mortreux M, Lieu S, Yu YY, Wurmser M, et al. Delayed bone regeneration is linked to chronic inflammation in murine muscular dystrophy. J Bone Miner Res. 2014;29(2):304-15. https://doi.org/10.1002/ jbmr.2038.

13. Patel RA, Wilson RF, Patel PA, Palmer RM. The effect of smoking on bone healing: a systematic review. Bone Joint Res. 2013;2(6):102-11. https://doi. org/10.1302/2046-3758.26.2000142.

14. Pscherer S, Sandmann GH, Ehnert S, Nussler AK, Stockle U, Freude T. Delayed fracture healing in diabetics with distal radius fractures. Acta Chir Orthop Traumatol Cechoslov. 2015;82(4):268-73.

15. Brown ML, Yukata K, Farnsworth CW, Chen DG, Awad H, Hilton MJ, et al. Delayed fracture healing and increased callus adiposity in a C57BL/6J murine model of obesity-associated type 2 diabetes mellitus. PLoS One. 2014;9(6):e99656. https://doi.org/10.1371/journal.pone.0099656.

16. Zheng SX, Vrindts Y, Lopez M, De Groote D, Zangerle PF, Collette J, et al. Increase in cytokine production (IL-1 beta, IL-6, TNF-alpha but not IFNgamma, GM-CSF or LIF) by stimulated whole blood cells in postmenopausal osteoporosis. Maturitas. 1997;26(1):63-71. https://doi.org/10.1016/S03785122(96)01080-8.

17. Wang JW, Li W, Xu SW, Yang DS, Wang Y, Lin M, et al. Osteoporosis influences the middle and late periods of fracture healing in a rat osteoporotic model. Chin J Traumatol. 2005;8(2):111-6.
18. Pang J, Ye M, Cao Y, Zheng Y, Guo H, Zhao Y, et al. Ovariectomy-induced osteopenia influences the middle and late periods of bone healing in a mouse femoral osteotomy model. Rejuvenation Res. 2014;18: 141009011509000. https://doi.org/10.1089/rej.2014.1590.

19. Chow SK, Chim YN, Wang JY, Wong RM, Choy VM, Cheung WH. Inflammatory response in postmenopausal osteoporotic fracture healing. Bone Joint Res. 2020;9(7):368-85. https://doi.org/10.1302/2046-3758.97.BJR-2 019-0300.R2.

20. Chow SK, Chim YN, Wang J, Zhang N, Wong RM, Tang N, et al. Vibration treatment modulates macrophage polarisation and enhances early inflammatory response in oestrogen-deficient osteoporotic-fracture healing. Eur Cell Mater. 2019;38:228-45. https://doi.org/10.22203/eCM.v038a16.

21. Zhang Q, Shi S, Liu Y, Uyanne J, Shi Y, Shi S, et al. Mesenchymal stem cells derived from human gingiva are capable of immunomodulatory functions and ameliorate inflammation-related tissue destruction in experimental colitis. J Immunol. 2009;183(12):7787-98. https://doi.org/10.4049/jimmunol. 0902318.

22. Wang W, Lin X, Xu H, Sun W, Bouta EM, Zuscik MJ, et al. Attenuated joint tissue damage associated with improved synovial lymphatic function following treatment with bortezomib in a mouse model of experimental posttraumatic osteoarthritis. Arthritis Rheum. 2019;71(2):244-57.

23. Henderson NC, Sethi T. The regulation of inflammation by galectin-3. Immunol Rev. 2009;230(1):160-71. https://doi.org/10.1111/j.1600-065X.2009. 00794.x.

24. Cho TJ, Gerstenfeld LC, Einhorn TA. Differential temporal expression of members of the transforming growth factor beta superfamily during murine fracture healing. J Bone Miner Res. 2002;17(3):513-20. https://doi.org/10.13 59/jbmr.2002.17.3.513.

25. Kon T, Cho TJ, Aizawa T, Yamazaki M, Nooh N, Graves D, et al. Expression of osteoprotegerin, receptor activator of NF-kappaB ligand (osteoprotegerin ligand) and related proinflammatory cytokines during fracture healing. J Bone Miner Res. 2001;16:1004-14 (0884-0431 (Print)).

26. Loi F, Córdova LA, Pajarinen J, Lin T-H, Yao Z, Goodman SB. Inflammation, fracture and bone repair. Bone. 2016;86:119-30. https://doi.org/10.1016/j. bone.2016.02.020

27. Kwan Tat S, Pelletier JP, Lajeunesse D, Fahmi H, Lavigne M, Martel-Pelletier J. The differential expression of osteoprotegerin (OPG) and receptor activator of nuclear factor kappaB ligand (RANKL) in human osteoarthritic subchondral bone osteoblasts is an indicator of the metabolic state of these disease cells. Clin Exp Rheumatol. 2008;26(2):295-304.

28. Ponte AL, Marais E, Gallay N, Langonne A, Delorme B, Herault O, et al. The in vitro migration capacity of human bone marrow mesenchymal stem cells: comparison of chemokine and growth factor chemotactic activities. Stem Cells. 2007;25(7):1737-45. https://doi.org/10.1634/stemcells.2007-0054.

29. Huang $H$, Zhao N, Xu X, Xu Y, Li S, Zhang J, et al. Dose-specific effects of tumor necrosis factor alpha on osteogenic differentiation of mesenchymal stem cells. Cell. 2011;44(5):420-7 (1365-2184 (Electronic)).

30. Aizawa T, Kon T, Einhorn TA, Gerstenfeld LC. Induction of apoptosis in chondrocytes by tumor necrosis factor-alpha. J Orthop Res. 2001;19(5):78596. https://doi.org/10.1016/50736-0266(00)00078-4.

31. Thomas CM, Whittles CE, Fuller CJ, Sharif M. Variations in chondrocyte apoptosis may explain the increased prevalence of osteoarthritis in some joints. Rheumatol Int. 2011;31(10):1341-8. https://doi.org/10.1007/s00296-01 $0-1471-9$.

32. Pearle AD, Scanzello CR, George S, Mandl LA, DiCarlo EF, Peterson M, et al. Elevated high-sensitivity C-reactive protein levels are associated with local inflammatory findings in patients with osteoarthritis. Osteoarthr Cartil. 2007; 15(5):516-23. https://doi.org/10.1016/j.joca.2006.10.010.

33. Kayal RA, Siqueira M, Alblowi J, McLean J, Krothapalli N, Faibish D, et al. TNF-alpha mediates diabetes-enhanced chondrocyte apoptosis during fracture healing and stimulates chondrocyte apoptosis through FOXO1. J Bone Miner Res. 2010;25(7):1604-15. https://doi.org/10.1002/jbmr.59.

34. Gerstenfeld LC, Cho TJ, Kon T, Aizawa T, Tsay A, Fitch J, et al. Impaired fracture healing in the absence of TNF-alpha signaling: the role of TNFalpha in endochondral cartilage resorption. J Bone Miner Res. 2003;18(9): 1584-92 (0884-0431 (Print)).

35. Zha L, He L, Liang Y, Qin H, Yu B, Chang L, et al. TNF-alpha contributes to postmenopausal osteoporosis by synergistically promoting RANKL-induced osteoclast formation. Biomed Pharmacother. 2018;102:369-74.

36. Hao YJ, Zhang G, Wang YS, Qin L, Hung WY, Leung K, et al. Erratum to "Changes of microstructure and mineralized tissue in the middle and late 
phase of osteoporotic fracture healing in rats" [Bone 41 (2007) 631-638] (DOl:10.1016/j.bone.2007.06.006). Bone. 2008;42(6):1240.

37. Fischer V, Kalbitz M, Muller-Graf F, Gebhard F, lgnatius A, Liedert A, et al. Influence of menopause on inflammatory cytokines during murine and human bone fracture healing. Int J Mol Sci. 2018;19(7):2070.

38. Haffner-Luntzer M, Fischer V, Prystaz K, Liedert A, Ignatius A. The inflammatory phase of fracture healing is influenced by oestrogen status in mice. Eur I Med Res. 2017;22(1):23. https://doi.org/10.1186/s40001-017-0264-y.

39. Kudo O, Sabokbar A, Pocock A, Itonaga I, Fujikawa Y, Athanasou NA. Interleukin-6 and interleukin-11 support human osteoclast formation by a RANKL-independent mechanism. Bone. 2003;32(1):1-7. https://doi.org/10.1 016/S8756-3282(02)00915-8.

40. Feng W, Liu H, Luo T, Liu D, Du J, Sun J, et al. Combination of IL-6 and sIL$6 R$ differentially regulate varying levels of RANKL-induced osteoclastogenesis through NF-kappaB, ERK and JNK signaling pathways. Sci Rep. 2017;7:41411.

41. Lange J, Sapozhnikova A, Lu C, Hu D, Li X, Miclau T 3rd, et al. Action of IL1 beta during fracture healing. J Orthop Res. 2010;28(6):778-84. https://doi. org/10.1002/jor.21061.

42. Schlundt C, El Khassawna T, Serra A, Dienelt A, Wendler S, Schell H, et al. Macrophages in bone fracture healing: their essential role in endochondral ossification. Bone. 2018;106:78-89. https://doi.org/10.1016/.bone.2015.10.019.

43. Jones CV, Ricardo SD. Macrophages and CSF-1: implications for development and beyond. Organogenesis. 2013;9(4):249-60. https://doi. org/10.4161/org.25676

44. Akagawa KS. Functional heterogeneity of colony-stimulating factor-induced human monocyte-derived macrophages. Int J Hematol. 2002;76(1):27-34. https://doi.org/10.1007/BF02982715.

45. Gordon S. Alternative activation of macrophages. Nat Rev Immunol. 2003; 3(1):23-35. https://doi.org/10.1038/nri978.

46. Rajasekaran M, Sul OJ, Choi EK, Kim JE, Suh JH, Choi HS. MCP-1 deficiency enhances browning of adipose tissue via increased M2 polarization. J Endocrinol. 2019;242(2):91-101. https://doi.org/10.1530/JOE-19-0190.

47. Gallagher KA, Obi AT, Elfline MA, Hogikyan E, Luke CE, Henke S, et al. Alterations in macrophage phenotypes in experimental venous thrombosis. J Vasc Surg Venous Lymphat Disord. 2016;4(4):463-71. https://doi.org/10.101 6/j.jvsv.2016.03.005

48. Jetten N, Verbruggen S, Gijbels MJ, Post MJ, De Winther MP, Donners MM. Anti-inflammatory M2, but not pro-inflammatory M1 macrophages promote angiogenesis in vivo. Angiogenesis. 2014;17(1):109-18. https://doi.org/10.1 007/s10456-013-9381-6.

49. Gong L, Zhao Y, Zhang Y, Ruan Z. The macrophage polarization regulates MSC osteoblast differentiation in vitro. Ann Clin Lab Sci. 2016;46(1):65-71.

50. Pettit AR, Chang MK, Hume DA, Raggatt LJ. Osteal macrophages: a new twist on coupling during bone dynamics. Bone. 2008;43(6):976-82. https:// doi.org/10.1016/j.bone.2008.08.128

51. Mantovani A, Biswas SK, Galdiero MR, Sica A, Locati M. Macrophage plasticity and polarization in tissue repair and remodelling. J Pathol. 2013; 229(2):176-85. https://doi.org/10.1002/path.4133.

\section{Publisher's Note}

Springer Nature remains neutral with regard to jurisdictional claims in published maps and institutional affiliations.

Ready to submit your research? Choose BMC and benefit from:

- fast, convenient online submission

- thorough peer review by experienced researchers in your field

- rapid publication on acceptance

- support for research data, including large and complex data types

- gold Open Access which fosters wider collaboration and increased citations

- maximum visibility for your research: over $100 \mathrm{M}$ website views per year

At $\mathrm{BMC}$, research is always in progress.

Learn more biomedcentral.com/submissions 